\title{
Health Risks due to Consumption of Malus domestica Golden Delicious Containing Heavy Metals
}

\author{
Reyna del Carmen Lara-Severino ${ }^{*}{ }^{\circledR}$, Julia G. Cerón Breton², Rosa M. Cerón Breton ${ }^{2}$, \\ Marcela Rangel Marrón'², Joaquín José Parra Pérez ${ }^{1}$ Octavio Manuel Nah Cabrera², \\ Elidesmeralda Abreu Félix ${ }^{2}$
}

\author{
${ }^{1}$ Sciences of Health Faculty, Autonomous University of Carmen, Ciudad del Carmen, Campeche, Mexico \\ ${ }^{2}$ Chemistry Faculty, Autonomous University of Carmen, Ciudad del Carmen, Campeche, Mexico \\ Email: *rclara@pampano.unacar.mx
}

How to cite this paper: del Carmen Lara-Severino, R., Breton, J.G.C., Breton, R.M.C., Marrón, M.R., Pérez, J.J.P., Cabrera, O.M.N. and Félix, E.A. (2019) Health Risks due to Consumption of Malus domestica Golden Delicious Containing Heavy Metals. Journal of Environmental Protection, 10, 577-594.

https://doi.org/10.4236/jep.2019.104033

Received: March 12, 2019

Accepted: April 19, 2019

Published: April 22, 2019

Copyright $\odot 2019$ by author(s) and Scientific Research Publishing Inc. This work is licensed under the Creative Commons Attribution International License (CC BY 4.0).

http://creativecommons.org/licenses/by/4.0/

\begin{abstract}
The intake of heavy metals through food consumption is a food safety problem that severely impacts the health of consumers, so information about food intake and heavy metal concentrations in food products is required to estimate the potential risk to the health of the population. The main purpose of this study was to estimate the potential risks to human health from exposure to $\mathrm{Cd}, \mathrm{Cu}, \mathrm{Ni}, \mathrm{Pb}$ and $\mathrm{Zn}$ through the intake of Malus domestica Golden Delicious consumed in the Mexican southeast, considering the age group and gender. The concentration of each of the metals was quantified by spectrometry of atomic absorption (AAE) and the daily intake of metals (DIM) and health risk indices through the consumption of apple: health risk index (HRI), total health risk index (THRI), target hazard coefficient (THQ) and the probability of carcinogenic risk (CR) were estimated. The concentrations of the metals analyzed in the apple samples showed the following decreasing order: $\mathrm{Zn} \geq \mathrm{Ni} \geq \mathrm{Cu} \geq \mathrm{Pb} \geq \mathrm{Cd}$. The DIM values showed the following decreasing order: child $>$ young adult $>$ adolescent $>$ elders. The health risk assessments (HRI, THRI, THQ and CR) obtained from the samples of Golden Delicious apples are located within the acceptable and/or tolerable limits, however, the increase in the intake of heavy metals through consumption of apples from establishments in the study area or the consumption of various foods contaminated with heavy metals may increase the health risk potential of consumers. For this reason, it is recommended to carry out studies on the concentration of heavy metals in food products, mainly those of greater popular consumption, to guarantee food security of the population.
\end{abstract}




\section{Keywords}

Apple, Heavy Metal Intake, Health Risk Assessment, Daily Intake and Carcinogenic Risk

\section{Introduction}

The consumption of contaminated food with heavy metals is one of the main routes of human exposure to these pollutants [1]. Hence, the accumulation of heavy metals in food represents a potential risk to the health of consumers.

The application of pesticides, fertilizers and fungicides based on heavy metals in crops has resulted in some foods being contaminated with various metals [2]. There are reports that heavy metals found in soil can be absorbed by plants and remain in their tissues [3], accumulating in food crops, thus contaminating the entire food chain [4].

Due to its physicochemical characteristics, non-biodegradability, bioaccumulation and biotoxicity [5], heavy metals can be toxic to the health of plants, animals and humans [6], causing in people serious issues, such as genomic instability, endocrine disruption, neurotoxicity, carcinogenicity, mutagenesis, teratogenesis, immunological problems and deteriorated psychosocial behavior [7] [8].

Several studies have been carried out [2] [9] [10] focused on the accumulation of heavy metals in various foods, particularly in vegetables and fruits and it has been reported that apple is one of the fruits with the highest accumulation of heavy metals, mainly cadmium $(\mathrm{Cd})$, copper $(\mathrm{Cu})$, nickel $(\mathrm{Ni})$, lead $(\mathrm{Pb})$ and zinc (Zn).

Recent studies have reported the presence of $\mathrm{Cd}, \mathrm{Cu}, \mathrm{Ni}, \mathrm{Pb}$ and $\mathrm{Zn}$ in Malus domestica (apple), a fruit of great economic importance, nutrimental value and broad consumption [2] [9]-[17]. For the above mentioned, it is important to continuously monitor the levels of these metals in Malus domestica, in order to ensure that its consumption does not represent a risk to the health of consumers.

The intake of heavy metals, such as $\mathrm{Cd}, \mathrm{Cu}, \mathrm{Ni}, \mathrm{Pb}$ and $\mathrm{Zn}$ can cause the depletion of some essential elements for the optimal functioning of the human organism [18], while the ingestion of food contaminated with $\mathrm{Cd}$ and $\mathrm{Pb}$ has been associated with toxic and adverse health effects, such as intrauterine growth retardation, decreased immune defenses, psychosocial behavioral disabilities associated with malnutrition and upper gastrointestinal cancer [19], hence the importance of estimating dietary exposure to a determined food or food matrix to assess the potential risk to human health from exposure to heavy metals through the intake of certain types of food.

The evaluation of dietary exposure is based on associating information about the consumption of certain foods with information about the concentration of the contaminant in order to estimate the potential risks to human health via oral exposure to the pollutant analyzed. 
Apple is one of the most consumed fresh fruits worldwide. It is estimated that 64.6 million tons are consumed annually [20]. In Mexico, apple is also one of the most consumed fruits, mainly grown in the north of the country. Its national consumption in 2016 was 931 thousand tons, with an annual consumption per capita of 7.6 Kg [21], being Malus domestica Golden Delicious (Golden Delicious apple) the species with the highest consumption nationwide.

Apple has been associated since unmemorable times with good health, also with great acceptability by consumers due to its freshness, juiciness, good taste, aroma and pleasant color, coupled with its nutritional composition consisting of potassium, phosphorus, calcium, iron, vitamin $\mathrm{A}, \mathrm{B}, \mathrm{C}, \mathrm{E}$, niacin, glucose and fructose [22]. It also contains various bioactive compounds with antioxidant properties, useful in preventing and reducing the risk of chronic non-communicable diseases and cancer [23], so it represents the basis of the diet of many people in our country, especially children and the elderly.

In Mexico, there are no enough reports on the concentration of heavy metals in Malus domestica Golden Delicious and the potential risks to human health due to its consumption, thus the objective of this study was to estimate the potential risks to human health by exposure to $\mathrm{Cd}, \mathrm{Cu}, \mathrm{Ni}, \mathrm{Pb}$ and $\mathrm{Zn}$ through the intake of Malus domestica Golden Delicious consumed in the Mexican southeast, considering the age group and gender.

\section{Materials and Methods}

\subsection{Analytical Equipment}

A Thermo Scientific iCE 3300 atomic absorption spectrometer was used for the determination of heavy metals. The operating conditions of the equipment are listed in Table 1.

\subsection{Reagents and Solutions}

All the reagents used in the determinations were analytical reactive grade. The standards of $\mathrm{Cd}, \mathrm{Cu}, \mathrm{Ni}, \mathrm{Pb}$ and $\mathrm{Zn}$, as well as the $\mathrm{HNO}_{3}$ used in the present study were atomic absorption grade (Merck). Work solutions of the above standards were prepared. The glass and polyethylene materials used in the present study were submerged overnight in a $10 \% \mathrm{HNO}_{3}$ solution, and subsequently, washed with ultra-high quality deionized water (UHQ, chemical resistance: 18 $\left.\mathrm{M} \Omega \mathrm{cm}^{-1}\right)$. Aliquots of the standard solutions $(10 \mathrm{mg} / \mathrm{L})$ containing the analyzed elements were used in the preparation of the calibration solutions. These solutions were prepared by serial dilutions with $0.2 \% \mathrm{HNO}_{3}$ prepared with deionized

Table 1. The operational conditions for analysis of selected heavy metals by spectrometer.

\begin{tabular}{cccccc}
\hline Parameters & $\mathrm{Cd}$ & $\mathrm{Cu}$ & $\mathrm{Ni}$ & $\mathrm{Pb}$ & $\mathrm{Zn}$ \\
\hline Acetylene/Air (L/min) & 1.2 & 1.1 & 0.9 & 1.1 & 1.2 \\
Slit width (nm) & 0.5 & 0.5 & 0.2 & 0.5 & 0.2 \\
Lamp current (mA) & 3 & 4 & 5 & 4 & 5 \\
\hline
\end{tabular}


water. The ranges of the calibration curves were selected according to the expected concentrations for $\mathrm{Cd}, \mathrm{Cu}$ and $\mathrm{Pb}(7$ points in a range of $0.03-0.9 \mathrm{mg} / \mathrm{L}), \mathrm{Ni}(5$ points in a range of $0.05-1.0 \mathrm{mg} / \mathrm{L}$ ) and $\mathrm{Zn}$ (5 points in a range of $0.5-2.5 \mathrm{mg} / \mathrm{L}$ ).

\subsection{Sampling Methodology}

The sampling was carried out in 2018, in 15 establishments (shopping centers, markets and greengrocers of Ciudad del Carmen, Campeche, Mexico) that sell Malus domestica Golden Delicious. Sampling was carried out in triplicate. In each of the sampled establishments, 3 samples of Malus domestica Golden Delicious were collected. All samples were washed with deionized water and dried with absorbent paper, then stored in clean polyethylene bags, hermetically sealed, labeled and stored in refrigeration for subsequent pretreatment, processing and quantification of metals.

\subsection{Pretreatment of Apple Samples}

The samples were taken out of the refrigerator and placed on the table until they reached room temperature, then, using a plastic knife and a glass board, the apples were cut into slices approximately $1 \mathrm{~cm}$ thick, which were placed in a drying oven at $70^{\circ} \mathrm{C}$ for 45 hours and then, the dried samples were ground in a mortar to obtain a fine powder. The pulverized samples were stored in polyethylene bags, labeled and hermetically sealed for further processing and quantification of metals.

\subsection{Processing of Apple Samples}

An analytical balance (3B Scientific, model AES 200) was used to weigh $0.5 \mathrm{~g}$ of the dried and milled apple sample and then placed in a $50 \mathrm{ml}$ beaker, adding 2 $\mathrm{ml}$ of a $30 \% \mathrm{H}_{2} \mathrm{O}_{2}$ solution (w/v) to preserve the sample for its germicidal action. The beaker was then placed on a heating plate with stirring (Thermo scientific Cimarec+) for 30 minutes until reaching a temperature of $150^{\circ} \mathrm{C}$, then $5 \mathrm{ml}$ of ultrapure $\mathrm{HNO}_{3}$ were added and digested for another $30 \mathrm{~min}$ at $150^{\circ} \mathrm{C}$. The digested sample was allowed to cool off and was filtered through a \#42 Whatman filter paper, the filtered solution was transferred to a $25 \mathrm{ml}$ volumetric flask and buffed with deionized water [2]. The volumetric solution was placed in a polyethylene bottle and kept refrigerated at $4^{\circ} \mathrm{C}$.

\subsection{Calibration Curves}

Calibration curves were prepared for the reading of heavy metals $(\mathrm{Cd}, \mathrm{Cu}, \mathrm{Ni}, \mathrm{Pb}$ and $\mathrm{Zn}$ ) based on certified standards.

\subsubsection{Linearity and Sensitivity}

The accuracy of the analytical procedures and the precision of the method for quantifying heavy metals by atomic absorption spectrometry were determined from the analysis of certified reference standards. The standards were treated the same as the samples. The quality control of the analysis considered the triplicate 
analysis of each sample with a confidence level of $99 \%$. A calibration curve was obtained from the concentration values of each heavy metal obtained in the atomic absorption equipment. This curve was fitted to a straight line using the weighted least squares model, and the slope of this line is the sensitivity of the method to determine the corresponding heavy metal. Each curve was constructed as the average curve of the three repetitions. Linearity was evaluated by the coefficient of determination $\left(R^{2}\right)$ and the regression coefficient $(r)$.

\subsubsection{Detection Limit}

The limit of detection of the analytical method for each heavy metal analyzed was calculated as twice the standard deviation of a series of measurements of a solution of the metal, by the following equation: $\mathrm{LD}(\mathrm{mg} / \mathrm{L})=[$ (Average metal concentration $)+2 \times($ standard deviation)] [24]. Each solution was prepared in triplicate.

\subsubsection{Quantification Limit}

The limit of quantification (LOQ) of each element was determined according to international accreditation criteria for laboratories that perform chemical food tests [25] (1999). For the determination of metal detection limits, two solutions were prepared for each sample and three individual readings were made for each solution. The mean of these readings was used to calculate the concentrations.

\subsection{Metal Quantification}

The samples were analyzed using a Thermo Scientific iCE 3300 atomic absorption equipment. This equipment operates with an air-acetylene flame, with a fuel flow of $1.2(1 / \mathrm{min})$ and $10(1 / \mathrm{min})$ of air. Hollow cathode photron lamps were used for each metal analyzed: $\mathrm{Cd}, \mathrm{Cu}, \mathrm{Ni}, \mathrm{Pb}$ and $\mathrm{Zn}$, using direct aspiration.

\subsection{Quality Guarantee}

To ensure the quality and reliability of the results, apple samples were carefully manipulated to avoid contamination with heavy metals. The glass material was washed with a $10 \% \mathrm{HNO}_{3}$ solution and then rinsed with deionized water. All the reagents used were analytical grade and the water used was deionized water. Determinations with reactive blanks were used to correct the readings of the equipment. For the validation of the analytical procedure, the \% recovery was obtained. The average recoveries obtained were $102.65 \% \pm 27.63 \%, 102.10 \% \pm$ $5.91 \%, 108.13 \% \pm 27.29 \%, 97.09 \% \pm 21.36 \%$ and $99.98 \% \pm 0.02 \%$ for $\mathrm{Cd}, \mathrm{Cu}, \mathrm{Ni}$, $\mathrm{Pb}$ and $\mathrm{Zn}$, respectively.

\subsection{Daily Intake of Metals}

The value of the daily intake of apple was obtained after analyzing 400 questionnaires applied to children (6 - 10 years), teenagers (11 - 19 years), young adults (20 - 49 years) and elders ( $>50$ years) (100 questionnaires for each age group). The survey focused on knowing the detailed apple consumption for a 
week. The daily metal consumption (DIM) was determined by age group, applying the following equation, according to the methodology proposed by [26].

$$
\mathrm{DIM}=\frac{C_{\text {metal }} \times C_{\text {factor }} \times D_{\text {food intake }}}{B_{\text {average weight }}}
$$

In Equation (1): DIM is the average of the daily consumption of the metal $\left(\mathrm{mg} / \mathrm{Kg} /\right.$ day), $C_{\text {metal }}$ is the average of the concentration of the heavy metal contained in Golden Delicious apple $(\mathrm{mg} / \mathrm{Kg}), C_{\text {factor }}$ is a conversion factor equal to 0.085 (to convert fresh weight to dry weight), $D_{\text {food intake }}$ is the average of the daily consumption of the fruit, obtained from the surveys (Kg/day) and $B_{\text {average weight }}$ is the average weight of the respondents grouped by age group (Kg). Additionally, in all calculations (DIM, HRI, THRI, THQ and CR) the effect of gender in the population was considered.

\subsection{Evaluation of Potential Risk to Health}

The chronic risk to health was estimated by consumption of Golden Delicious apples contaminated with heavy metals, as a health risk index (HRI) for each of the elements considered (Cd, $\mathrm{Cu}, \mathrm{Ni}, \mathrm{Pb}$ and $\mathrm{Zn}$ ) [26] [27] according to the following equation:

$$
\mathrm{HRI}=\frac{\mathrm{DIM}}{\mathrm{RfD}}
$$

In Equation (2): HRI is the risk index to health, DIM is the average of the daily consumption of the metal $(\mathrm{mg} / \mathrm{Kg} /$ day $)$ and $\mathrm{RfD}$ is the reference dose $(\mathrm{mg} / \mathrm{Kg} /$ day). The reference dose for $\mathrm{Cd}, \mathrm{Cu}, \mathrm{Ni}, \mathrm{Pb}$ and $\mathrm{Zn}$ are: 0.001, 0.04, 0.02, 0.004 and $0.30 \mathrm{mg} / \mathrm{kg} /$ day, as mentioned [26]. A value of $\mathrm{HR}<1$ indicates that the consumption of this fruit is safe and does not represent a danger to the health of the consuming population [12]. Additionally, the total health risk index (THRI) for heavy metals was determined as the sum of the individual values of each of the metals (Equation (3)). Like HRI, a value of THRI $<1$ indicates that the consumption of this fruit is safe and does not represent a danger to the health of the consuming population.

$$
\text { THRI }=\operatorname{HRI}\left(\operatorname{metal}_{1}\right)+\operatorname{HRI}\left(\operatorname{metal}_{2}\right)+\cdots+\operatorname{HRI}\left(\operatorname{metal}_{n}\right)
$$

The potential risk of exposure to $\mathrm{Cd}, \mathrm{Cu}, \mathrm{Ni}, \mathrm{Pb}$ and $\mathrm{Zn}$ by ingestion of apple was estimated by calculating the target hazard coefficient (THQ), which is the relationship between the estimated exposure and the oral reference dose, using the following equation [28] [29]:

$$
\mathrm{THQ}=\frac{\mathrm{EF} \times \mathrm{ED} \times \mathrm{IR} \times C}{\mathrm{RfD} \times \mathrm{Bw} \times \mathrm{AT}}
$$

In Equation (4): THQ is the objective hazard coefficient, $\mathrm{EF}$ is the frequency of exposure, in days/year (365 days/year), ED is the duration of exposure, in years (life expectancy for Mexican adults), IR is the apple ingestion rate (Kg/day), $C$ is the average heavy metal concentration contained in fruits $(\mathrm{mg} / \mathrm{Kg}), \mathrm{RfD}$ is the oral reference dose for $\mathrm{Cd}, \mathrm{Cu}, \mathrm{Ni}, \mathrm{Pb}$ and $\mathrm{Zn}(0.001,0.04,0.02,0.004$ and 0.30 
$\mathrm{mg} / \mathrm{Kg} /$ day), respectively [26], BW is the average weight of the respondents grouped by age group $(\mathrm{Kg})$ and $\mathrm{AT}$ is the average exposure time (days). THQ values between 1 and 5 indicate that consumers to some extent are warning of adverse effects on their health [30].

The probability of carcinogenic risk (CR) for heavy metal intake through Golden Delicious apples was calculated based on the USEPA carcinogenic slope for each metal analyzed according to the following equation [31]:

$$
\mathrm{CR}=\mathrm{EDI} \times \mathrm{CSFing}
$$

In Equation (5): EDI is the estimated daily intake of each of the heavy metals analyzed $(\mathrm{mg} / \mathrm{Kg} /$ day), CSFing is the carcinogenic slope factor by ingestion for $\mathrm{Cd}$, $\mathrm{Ni}$ and $\mathrm{Pb}(0.38,1.7 \text { and } 0.0085 \mathrm{mg} / \mathrm{Kg} / \mathrm{day})^{-1}$, respectively, as mentioned [31].

The estimated daily intake (EDI) was determined by the following equation [31]:

$$
\mathrm{EDI}=\frac{C_{\text {metal }} \times \text { Daily intake }}{\mathrm{Bw}}
$$

In Equation (6): $C_{\text {metal }}$ is the average concentration of the metal $(\mathrm{mg} / \mathrm{Kg})$ and daily intake $(\mathrm{Kg} /$ day $)$ is the average consumption of the fruit by group and gender, body weight $(\mathrm{Kg})$, is the average weight of the participants by group and gender. The risk is considered acceptable or tolerable when $\mathrm{CR}$ is within the range of $10^{-6}$ to $10^{-4}[31]$.

\section{Results and Discussion}

\subsection{Sensitivity, Linearity and Detection Limit}

Table 2 shows the calibration curves obtained from a weighted regression using the least squares model, the sensitivities are the slope of the curves of $\mathrm{Cd}, \mathrm{Cu}, \mathrm{Ni}$, $\mathrm{Pb}$ and $\mathrm{Zn}$. Table 2 shows the coefficient of determination $\left(R^{2}\right)$ and the coefficient of linear regression $(r)$. The first indicates how well the model fits the data, in our case, the model is a straight line. This is a measure that allows us to determine how sure we can be when making predictions from a particular model or chart. The second coefficient measures the strength and direction of the linear relationship between the two variables. In this case, both coefficients are higher

Table 2. Calibration curves for determination of $\mathrm{Cd}, \mathrm{Cu}, \mathrm{Ni}, \mathrm{Pb}$ y $\mathrm{Zn}$ using atomic absorption spectrometry (AAE).

\begin{tabular}{cccccc}
\hline Heavy metals & $\begin{array}{c}\text { Wavelength } \\
(\mathrm{nm})\end{array}$ & Calibration curve & $\begin{array}{c}\text { Determination } \\
\text { coefficient }\left(R^{2}\right)\end{array}$ & $\begin{array}{c}\text { Regression } \\
\text { coefficient }(r)\end{array}$ & $\begin{array}{c}\text { Detection } \\
\text { limit }(\mathrm{mg} / \mathrm{L})\end{array}$ \\
\hline $\mathrm{Cd}$ & $228.8 \mathrm{~nm}$ & $y=0.3497 x-0.0019$ & 0.999 & 0.999 & 0.03 \\
$\mathrm{Cu}$ & $324.8 \mathrm{~nm}$ & $y=0.1179 x-0.0015$ & 0.999 & 0.999 & 0.03 \\
$\mathrm{Ni}$ & $232.0 \mathrm{~nm}$ & $y=0.0880 x-0.0011$ & 0.996 & 0.997 & 0.05 \\
$\mathrm{~Pb}$ & $217.0 \mathrm{~nm}$ & $y=0.0484 x-0.0008$ & 0.999 & 0.999 & 0.03 \\
$\mathrm{Zn}$ & $213.9 \mathrm{~nm}$ & $y=0.3917 x+0.0377$ & 0.996 & 0.997 & 0.50 \\
\hline
\end{tabular}


than 0.996 , which indicates that a straight line is a very suitable model to adjust our data (concentration of heavy metal analyzed vs. absorbance) for the 5 methods of atomic absorption spectroscopy within the range of concentration analyzed; The linear relationship between both variables is strong and positive, since increasing the concentration of the analyte $(\mathrm{Cd}, \mathrm{Cu}, \mathrm{Ni}, \mathrm{Pb}$ or $\mathrm{Zn})$ increases the absorbance signal.

\subsection{Malus domestica Golden Delicious Intake by Age Group}

After the application of the 400 surveys (100 for each age group) administered to the respondents who voluntarily decided to answer the questionnaire prepared exprofeso to assess the average daily intake of apples by age group and gender, were obtained the intake values that are illustrated in Table 3.

In this table it can be seen that the average values of the daily Golden Delicious apple intake among the surveyed population are similar among them regardless of the age group and gender, showing the following decreasing order: young adult $\geq$ teenagers $\geq$ elders and children, while other authors have reported an average consumption of 61 and $12.7 \mathrm{~g} /$ day of apple, respectively [32] [33].

\subsection{Trace Metals Determination}

Heavy metals concentrated in an apple, not only affects their nutritional value, but also can accumulate in the body of people who ingest this fruit and cause serious toxic effects to their health, so, with the purpose of preserving the quality of food and as part of the food security of the population there are national and international regulations that have established the maximum permissible limits of various heavy metals in foods for human consumption (as some authors point out [15] [16]) in order to monitor the concentrations of these metals in food.

The average concentrations of $\mathrm{Cd}, \mathrm{Cu}, \mathrm{Ni}, \mathrm{Pb}$ and $\mathrm{Zn}$ found in the samples of apples are shown in Table 4 and were compared with the results of concentrations of $\mathrm{Cd}, \mathrm{Cu}, \mathrm{Ni}, \mathrm{Pb}$ and $\mathrm{Zn}$ reported in apples, by other authors.

In Table 4, it can be seen that within the heavy metals analyzed in this research, it was found that $\mathrm{Zn}$ and $\mathrm{Cd}$ have the highest and lowest concentrations,

Table 3. Average daily intake of Malus domestica Golden Delicious by age group and gender.

\begin{tabular}{cccccccccc}
\hline Age group & \multicolumn{6}{c}{ Average daily intake (g) by group and gender } \\
\hline & \multicolumn{2}{c}{ Total } & & F & & M & \\
\hline & g & n & g & n & g & n \\
\hline Children (6 - 10 years) & 53 & 100 & 53 & 47 & 53 & 53 \\
Teenagers (11 - 19 years) & 54 & 100 & 51 & 55 & 58 & 45 \\
Young adults (20 - 49 years) & 58 & 100 & 59 & 66 & 55 & 34 \\
Elders (>50 years) & 53 & 100 & 53 & 72 & 54 & 38 \\
\hline
\end{tabular}

$\mathrm{F}$, is female; $\mathrm{M}$, is male; $\mathrm{g}$, is gram; $\mathrm{n}$, is the number of people that make up the sample by age group and by gender. 
Table 4. Heavy metals content ( $\mathrm{Cd}, \mathrm{Cu}, \mathrm{Ni}, \mathrm{Pb}$ y $\mathrm{Zn}$ ) found in other studies and their comparison to those found in this study.

\begin{tabular}{ccccccc}
\hline \multicolumn{5}{c}{ Heavy metals concentrations $(\mathrm{mg} / \mathrm{kg}$ dry weigh) } & \multirow{2}{*}{ Reference } \\
\cline { 1 - 4 } $\mathrm{Cd}$ & $\mathrm{Cu}$ & $\mathrm{Ni}$ & $\mathrm{Pb}$ & $\mathrm{Zn}$ & \\
\hline$<0.03$ & 0.06 & 0.08 & 0.05 & 1.51 & This study \\
0.06 & - & 12.23 & 0.32 & 7.62 & {$[9]$} \\
0.16 & 0.19 & 0.42 & 2.21 & 4.26 & {$[10]$} \\
0.0006 & - & 0.06 & 0.01 & - & {$[11]$} \\
0.08 & 0.09 & 0.19 & - & 0.04 & {$[12]$} \\
0.001 & - & - & 0.01 & - & {$[13]$} \\
0.004 & 0.003 & 0.11 & 0.11 & 0.04 & {$[15]$} \\
0.05 & 1.47 & - & 0.19 & 1.36 & {$[16]$} \\
0.06 & 0.15 & 1.76 & 3.20 & 0.06 & {$[34]$} \\
0.54 & 1.13 & 2.43 & 0.62 & 4.06 & {$[35]$} \\
- & 0.25 & - & - & 0.16 & {$[36]$} \\
0.14 & 0.50 & - & 0.76 & 2.05 & {$[37]$} \\
\hline
\end{tabular}

respectively, compared to the other metals. The concentration levels of the metals analyzed showed the following decreasing order: $\mathrm{Zn} \geq \mathrm{Ni} \geq \mathrm{Cu} \geq \mathrm{Pb} \geq \mathrm{Cd}$.

The average concentration of $\mathrm{Cd}$ found in apple samples (Table 4 ) was $<0.03$ $\mathrm{mg} / \mathrm{kg}$, which is below the permissible limit $(0.1 \mathrm{mg} / \mathrm{kg})$ established by [38]. In this study, the Cd concentration was lower than the concentrations reported by [9] [10] [12] [16] [34] [35] [37] in apple samples from Egypt, Nigeria, Pakistan and Turkey, respectively. Cd is a heavy metal classified [8] as carcinogenic to humans, it is highly persistent and toxic, present in low concentrations in the environment, predominating in associations with $\mathrm{Zn}, \mathrm{Pb}$ and $\mathrm{Cu}$, it accumulates especially in kidneys and liver affecting human health through sources of occupational and environmental exposure [39]. Since the consumption of food contaminated with $\mathrm{Cd}$ is its main source of exposure in the nonsmoking population, its long-term exposure even at low concentrations can cause damage to the kidneys, liver, bones and cardiovascular system, hearing impairment and sight, and lung, breast, prostate, pancreas, urinary bladder and nasopharynx cancer [39] [40]. Even though the average concentration of Cd found in the apples sampled was lower than the limit of detection of this metal in the spectrometer used $(\mathrm{Cd}$ $<0.03 \mathrm{mg} / \mathrm{Kg}$ ), it is necessary to continuously monitor its presence and concentration in food crops in order to reduce the health risk associated with exposure to this dangerous metal.

Average $\mathrm{Cu}$ concentration $(0.06 \mathrm{mg} / \mathrm{kg}$ ) obtained in this study (Table 4) showed a value below the permissible limit $(73 \mathrm{mg} / \mathrm{kg}$ ) established by [38]. In our study, the concentration of $\mathrm{Cu}$ in apples coincides in order of magnitude with that reported by [12] in samples of apples collected in Pakistan, this concentration being lower than that reported by [10] [12] [16] [34] [35] [36] [37] in 
apple samples from Egypt, Nigeria, Pakistan and Turkey, respectively. $\mathrm{Cu}$ is an essential micronutrient that acts as a biocatalyst, and in conjunction with iron is required to give pigmentation to the body, it also helps keep the central nervous system healthy and prevents anemia [15], since some plants require $\mathrm{Cu}$ to its optimal growth, sometimes, this metal is added to crops through fertilizers, so it is necessary to monitor its concentration in food crops, since poor agricultural practices could increase the risk to health from exposure to this metal through food.

The average concentration of $\mathrm{Ni}(0.08 \mathrm{mg} / \mathrm{Kg})$ found in this study (Table 4) was below the permissible limit $(67 \mathrm{mg} / \mathrm{kg})$ [38], this value is slightly higher $(0.06 \mathrm{mg} / \mathrm{Kg})$ than reported in samples of apples grown in China [11] and lower than that reported in samples of apples collected in different sites in Nigeria, Pakistan and Turkey, respectively [9] [10] [12] [15] [34] [35] (Table 4). About health effects, exposure to $\mathrm{Ni}$ has been reported to cause skin allergies, pulmonary fibrosis, cytotoxicity, iatrogenic nickel poisoning and cancer of the respiratory tract, lung cancer and nasal cancer [41].

Average concentration for $\mathrm{Pb}(0.05 \mathrm{mg} / \mathrm{Kg})$ (Table 4) was lower than the permissible limit $(0.3 \mathrm{mg} / \mathrm{Kg})$ [38] and higher than that reported in samples of apples collected in production areas of China and in different supermarkets in Serbia [11] [13]. Reported $\mathrm{Pb}$ concentrations in samples of apples from Egypt, Nigeria, Turkey and Pakistan [9] [10] [15] [16] [34] [35] [37] are higher than the concentration found in our study. $\mathrm{Pb}$ has been classified as a possible human carcinogen, and there are also reports that this metal can cause neurological, renal, cardiovascular, hematological, reproductive and gastrointestinal effects [41], which is why the introduction of this metal should be avoided in the food chain, since its accumulation in the human organism can lead to serious health problems.

$\mathrm{Zn}$ average concentration (Table 4) found in this study was of $1.51 \mathrm{mg} / \mathrm{Kg}$, which was lower than the permissible limit $(9.4 \mathrm{mg} / \mathrm{Kg})$ [38], higher than that reported in samples from Egypt, Nigeria and Pakistan, respectively [12] [15] [16] [34] [36], and lower than those values reported in apple samples collected in $\mathrm{Pa}$ kistan and Turkey [9] [10] [35] [37], respectively. $\mathrm{Zn}$ is an essential metal for various biochemical and physiological functions, its deficiency can cause immunological alterations.

In our study, all concentrations of heavy metals analyzed in the samples of apples collected in the study area were within the permissible limits established [38], in turn, these concentrations were several times lower than the concentrations reported for $\mathrm{Cd}, \mathrm{Cu}, \mathrm{Ni}, \mathrm{Pb}$ and $\mathrm{Zn}$, respectively [9] [10] [16] [34]. With regard to the presence of metal in food crops, Mapanda and collaborators [42] reports that a higher heavy metal concentration in soil corresponds in a greater probability that a given metal is present in the crops and its concentration in the food will depend on the soil, the degree of air pollution and the capacity of crop absorption, among other factors [28], this could explain the differences and similarities between the concentrations of $\mathrm{Cd}, \mathrm{Cu}, \mathrm{Ni}, \mathrm{Pb}$ and $\mathrm{Zn}$ obtained in this 
study and the concentrations reported by the authors listed in Table 4 .

\subsection{Health Risk Assessment}

The ingestion of heavy metals through the consumption of food is a very important problem because of its implications for human health. The calculated values of DIM, HRI and THQ are shown in Table 5 by age group (children, teenagers, young adults and elders) and by gender.

Table 5. Evaluation of health risk potential by consumption of Malus domestica Golden Delicious containing $\mathrm{Cd}, \mathrm{Cu}, \mathrm{Ni}, \mathrm{Pb}$ and $\mathrm{Zn}$ by age group and by gender.

\begin{tabular}{|c|c|c|c|c|c|c|c|c|c|c|c|c|}
\hline \multicolumn{13}{|c|}{$\mathrm{Cd}$} \\
\hline & \multicolumn{3}{|c|}{ Children } & \multicolumn{3}{|c|}{ Teenagers } & \multicolumn{3}{|c|}{ Young Adult } & \multicolumn{3}{|c|}{ Elders } \\
\hline & Total & $\mathrm{F}$ & M & Total & F & M & Total & $\mathrm{F}$ & M & Total & $\mathrm{F}$ & M \\
\hline $\operatorname{DIM}\left(10^{-06}\right)$ & 4.40 & 4.59 & 4.22 & 2.27 & 2.32 & 2.20 & 2.31 & 2.51 & 1.90 & 1.95 & 2.02 & 1.82 \\
\hline HRI $\left(10^{-04}\right)$ & 44.03 & 45.99 & 42.29 & 22.70 & 23.27 & 22.01 & 23.11 & 25.18 & 19.08 & 19.50 & 20.24 & 18.29 \\
\hline THQ $\left(10^{-03}\right)$ & 51.80 & 54.11 & 49.75 & 26.71 & 27.38 & 25.90 & 27.19 & 29.63 & 22.45 & 22.94 & 23.81 & 21.52 \\
\hline \multicolumn{13}{|c|}{$\mathrm{Cu}$} \\
\hline & \multicolumn{3}{|c|}{ Children } & \multicolumn{3}{|c|}{ Teenagers } & \multicolumn{3}{|c|}{ Young Adult } & \multicolumn{3}{|c|}{ Elders } \\
\hline & Total & $\mathrm{F}$ & M & Total & F & M & Total & $\mathrm{F}$ & M & Total & F & M \\
\hline $\operatorname{DIM}\left(10^{-06}\right)$ & 8.80 & 9.19 & 8.45 & 4.54 & 4.65 & 4.40 & 4.62 & 5.03 & 3.81 & 3.90 & 4.04 & 3.65 \\
\hline HRI $\left(10^{-04}\right)$ & 2.20 & 2.29 & 2.11 & 1.13 & 1.16 & 1.10 & 1.15 & 1.25 & 0.95 & 0.97 & 1.01 & 0.91 \\
\hline THQ $\left(10^{-03}\right)$ & 2.59 & 2.70 & 2.48 & 1.33 & 1.36 & 1.29 & 1.35 & 1.48 & 1.12 & 1.14 & 1.19 & 1.07 \\
\hline \multicolumn{13}{|c|}{$\mathrm{Ni}$} \\
\hline & \multicolumn{3}{|c|}{ Children } & \multicolumn{3}{|c|}{ Teenagers } & \multicolumn{3}{|c|}{ Young Adult } & \multicolumn{3}{|c|}{ Elders } \\
\hline & Total & $\mathrm{F}$ & M & Total & $\mathrm{F}$ & M & Total & $\mathrm{F}$ & M & Total & $\mathrm{F}$ & M \\
\hline $\operatorname{DIM}\left(10^{-06}\right)$ & 11.74 & 12.26 & 11.27 & 6.05 & 6.20 & 5.87 & 6.16 & 6.71 & 5.08 & 5.20 & 5.39 & 4.87 \\
\hline HRI $\left(10^{-04}\right)$ & 5.87 & 6.13 & 5.63 & 3.02 & 3.10 & 2.93 & 3.08 & 3.35 & 2.54 & 2.60 & 2.69 & 2.43 \\
\hline THQ $\left(10^{-03}\right)$ & 6.90 & 7.21 & 6.63 & 3.56 & 3.65 & 3.45 & 3.62 & 3.95 & 2.99 & 3.05 & 3.17 & 2.86 \\
\hline \multicolumn{13}{|c|}{$\mathrm{Pb}$} \\
\hline & \multicolumn{3}{|c|}{ Children } & \multicolumn{3}{|c|}{ Teenagers } & \multicolumn{3}{|c|}{ Young Adult } & \multicolumn{3}{|c|}{ Elders } \\
\hline & Total & $\mathrm{F}$ & M & Total & $\mathrm{F}$ & M & Total & $\mathrm{F}$ & M & Total & $\mathrm{F}$ & M \\
\hline $\operatorname{DIM}\left(10^{-06}\right)$ & 7.33 & 7.66 & 7.04 & 3.78 & 3.87 & 3.66 & 3.85 & 4.19 & 3.18 & 3.25 & 3.37 & 3.04 \\
\hline HRI $\left(10^{-04}\right)$ & 18.34 & 19.16 & 17.62 & 9.46 & 9.69 & 9.17 & 9.63 & 10.49 & 7.95 & 8.12 & 8.43 & 7.62 \\
\hline THQ $\left(10^{-03}\right)$ & 21.58 & 22.54 & 20.73 & 11.13 & 11.40 & 10.79 & 11.33 & 12.34 & 9.35 & 9.56 & 9.92 & 8.96 \\
\hline \multicolumn{13}{|c|}{$\mathrm{Zn}$} \\
\hline & \multicolumn{3}{|c|}{ Children } & \multicolumn{3}{|c|}{ Teenagers } & \multicolumn{3}{|c|}{ Young Adult } & \multicolumn{3}{|c|}{ Elders } \\
\hline & Total & $\mathrm{F}$ & M & Total & $\mathrm{F}$ & M & Total & $\mathrm{F}$ & M & Total & $\mathrm{F}$ & M \\
\hline $\operatorname{DIM}\left(10^{-06}\right)$ & 221.64 & 231.52 & 212.88 & 114.29 & 117.14 & 110.81 & 116.33 & 126.78 & 96.06 & 98.16 & 101.89 & 92.08 \\
\hline HRI $\left(10^{-04}\right)$ & 7.38 & 7.71 & 7.09 & 3.80 & 3.90 & 3.69 & 3.87 & 4.22 & 3.20 & 3.27 & 3.39 & 3.06 \\
\hline THQ $\left(10^{-03}\right)$ & 8.69 & 9.07 & 8.34 & 4.48 & 4.59 & 4.34 & 4.56 & 4.97 & 3.76 & 3.84 & 3.99 & 3.61 \\
\hline
\end{tabular}

DIM, is the average daily consumption of the metal ( $\mathrm{mg} / \mathrm{Kg} /$ day); HRI is the health risk index (dimensionless); THQ is the objective (dimensionless) hazard coefficient, $F$, is female; $M$, is male. 
The concentrations of $\mathrm{Cd}$ (Table 4) were below the detection limits of the equipment for this metal, so the value of the detection limit was used to calculate the DIM, HRI, THRI, THQ and CR values of this metal $(0.03 \mathrm{mg} / \mathrm{kg})$ to determine said parameters.

Comparing DIM concentrations by metal analyzed, the following trend is found: $\mathrm{Zn}>\mathrm{Ni}>\mathrm{Cu}>\mathrm{Pb}<\mathrm{Cd}$. The average DIM value (Table 5) of each of the analyzed metals shows lower values than those reported in samples of apples collected in China, in samples of vegetables collected in China and in food from Saudi Arabia, respectively [2] [27] [43]. DIM found values considering each age group showed the following decreasing order: child > young adult $>$ teenagers $>$ elders. DIM values were higher in the female population in comparison with the values obtained for male population, registering generally a smaller corporal weight in the females in comparison with the males.

The potential risks to health associated with the consumption of $\mathrm{Cd}, \mathrm{Cu}, \mathrm{Ni}$, $\mathrm{Pb}$ and $\mathrm{Zn}$ were evaluated through dietary intake of Golden Delicious apple. To estimate the human health risk index through the consumption of apples, the HRI was calculated (Table 5) and values less than 1 were found for each of the metals analyzed in each age group and by gender. It can be concluded that the consumption of Golden Delicious apple from the study area is safe for residents and does not pose a significant potential risk to the health of consumers. The HRI values for metal analyzed show the following decreasing order: $\mathrm{Cd}>\mathrm{Pb}>$ $\mathrm{Zn}>\mathrm{Ni}>\mathrm{Cu}$.

The average HRI values of each of the metals analyzed showed the following decreasing order: child $>$ young adult $>$ teenagers $>$ elders, presenting higher values in the female population compared to the HRI values in the male population. The HRI values shown in Table 5 were lower than reported for $\mathrm{Cu}$ and $\mathrm{Ni}$ and higher for $\mathrm{Zn}$ in apple samples from Pakistan [12], and similar for $\mathrm{Zn}$ in foods from Saudi Arabia [43], and for $\mathrm{Cu}$ and $\mathrm{Zn}$ in samples of vegetables grown in Dubai [44], respectively.

On the other hand, the objective risk quotient (THQ) was calculated to estimate potential health risks (non-carcinogenic risk) associated with long-term exposure to chemical pollutants, in this case, $\mathrm{Cd}, \mathrm{Cu}, \mathrm{Ni}, \mathrm{Pb}$ and $\mathrm{Zn}$. The THQ values (Table 5) calculated individually for each of the heavy metals analyzed are located below 1, which coincides with that reported by [28] for $\mathrm{Cu}, \mathrm{Pb}$ and $\mathrm{Zn}$ in fruit samples grown in Romania and slightly higher than that reported in $\mathrm{Cu}$ and $\mathrm{Zn}$ by [29] in fruits marketed in Algerian markets. The THQ values for metal analyzed show the following decreasing order: $\mathrm{Cd}>\mathrm{Pb}>\mathrm{Zn}>\mathrm{Ni}>\mathrm{Cu}$.

HRI and THQ values less than 1 indicate that the potential adverse health effects of people who consume apples from the study sites are not affordable, that is, these people may not present significant health risks due to intake of $\mathrm{Cd}, \mathrm{Cu}$, $\mathrm{Ni}, \mathrm{Pb}$ and $\mathrm{Zn}$ through the consumption of apples. However, the consumption of various foods contaminated with the same heavy metal could cause a potential risk to the health of the consumers of those mentioned foods, since the HRI and THQ value of each of these foods could contribute to this value being greater 
than 1.

THQ values of each of the analyzed metals showed the following decreasing order: child $>$ young adult $>$ teenagers $>$ elders, presenting higher values in female population compared with those THQ values found in male population.

Total health risk index (THRI) was determined as the sum of the individual values of the HRIs of each of the metals analyzed (Table 6), resulting in values lower than 1 in all genders and age groups, so that the consumption of apples is safe and it does not represent a significant risk to the health of the resident consumers.

The carcinogenic risk is evaluated and expressed as the probability of suffering cancer throughout the life of 70 years. The calculation of the probability of carcinogenic risk (CR) by ingestion of heavy metals consumed through apples showed $\mathrm{CR}$ values of the order of $10^{-4}$ for $\mathrm{Ni}, 10^{-5}$ for $\mathrm{Cd}$ and $10^{-7}$ for $\mathrm{Pb}$ ( Table $7)$, respectively. The values obtained from $\mathrm{CR}$ for $\mathrm{Ni}\left(10^{-4}\right)$ are considered unacceptable [31], so there is a slight concern for CR induced by Ni through the consumption of apples; whereas, $\mathrm{CR}$ for $\mathrm{Pb}\left(10^{-7}\right)$ and $\mathrm{Cd}\left(10^{-5}\right)$ are within the acceptable range, which suggests a potential $\mathrm{CR}$ no for intake of $\mathrm{Pb}$ and $\mathrm{Cd}$ through the consumption of apples. Except for the best knowledge of the authors, CSFing

Table 6. Assessment of the total health risk index for consumption of Malus domestica Golden Delicious containing $\mathrm{Cd}, \mathrm{Cu}, \mathrm{Ni}, \mathrm{Pb}$ and $\mathrm{Zn}$ by gender and age group.

\begin{tabular}{cccccccccccccc}
\hline \multicolumn{10}{c}{ THRI } \\
\hline \multicolumn{1}{c}{ Children } & \multicolumn{1}{c}{ Teenagers } & \multicolumn{3}{c}{ Young Adult } & & \multicolumn{2}{c}{ Elders } \\
\hline \multirow{2}{*}{ Total } & F & M & Total & F & M & Total & F & M & Total & F & M \\
\hline 0.0077 & 0.0081 & 0.0074 & 0.0040 & 0.0041 & 0.0038 & 0.0040 & 0.0044 & 0.0033 & 0.0034 & 0.0035 & 0.0032
\end{tabular}

THRI, is the total health risk index; $\mathrm{F}$, is female; $\mathrm{M}$, is male.

Table 7. Probability of carcinogenic risk (CR) due to ingestion of heavy metals consumed through Malus domestica Golden Delicious by gender and age group.

\begin{tabular}{|c|c|c|c|c|c|c|c|c|c|c|c|c|}
\hline \multicolumn{13}{|c|}{ CR Cd } \\
\hline & \multicolumn{3}{|c|}{ Children } & \multicolumn{3}{|c|}{ Teenagers } & \multicolumn{3}{|c|}{ Young Adult } & \multicolumn{3}{|c|}{ Elders } \\
\hline & Total & $\mathrm{F}$ & $\mathrm{M}$ & Total & $\mathrm{F}$ & M & Total & $\mathrm{F}$ & $\mathrm{M}$ & Total & $\mathrm{F}$ & M \\
\hline $\mathrm{CR}\left(10^{-05}\right)$ & 1.96 & 2.05 & 1.89 & 1.01 & 1.04 & 0.98 & 1.03 & 1.12 & 0.85 & 0.87 & 0.90 & 0.81 \\
\hline \multicolumn{13}{|c|}{$\mathrm{CR} \mathrm{Ni}$} \\
\hline & \multicolumn{3}{|c|}{ Children } & \multicolumn{3}{|c|}{ Teenagers } & \multicolumn{3}{|c|}{ Young Adult } & \multicolumn{3}{|c|}{ Elders } \\
\hline & Total & $\mathrm{F}$ & M & Total & $\mathrm{F}$ & M & Total & $\mathrm{F}$ & M & Total & $\mathrm{F}$ & $\mathrm{M}$ \\
\hline $\operatorname{CR}\left(10^{-04}\right)$ & 2.34 & 2.45 & 2.25 & 1.21 & 1.24 & 1.17 & 1.23 & 1.34 & 1.01 & 1.04 & 1.07 & 0.97 \\
\hline \multicolumn{13}{|c|}{$\mathrm{CR} \mathrm{Pb}$} \\
\hline & \multicolumn{3}{|c|}{ Children } & \multicolumn{3}{|c|}{ Teenagers } & \multicolumn{3}{|c|}{ Young Adult } & \multicolumn{3}{|c|}{ Elders } \\
\hline & Total & $\mathrm{F}$ & M & Total & $\mathrm{F}$ & M & Total & $\mathrm{F}$ & M & Total & $\mathrm{F}$ & M \\
\hline $\mathrm{CR}\left(10^{-07}\right)$ & 7.33 & 7.66 & 7.04 & 3.78 & 3.87 & 3.66 & 3.85 & 4.19 & 3.18 & 3.25 & 3.37 & 3.04 \\
\hline
\end{tabular}

$\mathrm{CR}$, is the carcinogenic risk (dimensionless), $\mathrm{F}$, is female; $\mathrm{M}$, is male. 
values for $\mathrm{Cu}$ and $\mathrm{Zn}$ are not available, reason for which the $\mathrm{CR}$ of these metals was not calculated.

Results of $\mathrm{CR}$ for $\mathrm{Ni}$ were lower than those reported in snail samples from Nigeria [31], and for $\mathrm{Cd}$ and $\mathrm{Pb}$ were slightly below than those reported in samples of snail from Nigeria [31]. The results of CR for Ni showed the following decreasing order: child $>$ young adult $>$ teenagers $>$ elders, presenting higher $\mathrm{CR}$ values in the female population compared to $\mathrm{CR}$ values in the male population, following the same behavior pattern for $\mathrm{CR}$ for $\mathrm{Cd}$ and $\mathrm{Pb}$.

\section{Conclusions}

The ingestion of heavy metals through the consumption of food is a problem of food safety that has important implications for human health, so heavy metals contained in Malus domestica Golden Delicious marketed in the Mexican southeast were investigated. The concentrations of heavy metals in apples showed the following decreasing order: $\mathrm{Zn} \geq \mathrm{Ni} \geq \mathrm{Cu} \geq \mathrm{Pb} \geq \mathrm{Cd}$, being within the permissible limits [38] for each of these metals.

The values obtained from HRI indicate that the consumption of Malus domestica Golden Delicious sampled in the study area is free of a health risk index by intake of $\mathrm{Cd}, \mathrm{Cu}, \mathrm{Ni}, \mathrm{Pb}$ and $\mathrm{Zn}$ in all the age groups studied and by gender. The THQ values obtained indicate that the consumption of apples sampled in the study area has little potential for health risk for non-carcinogenic effects. Regarding the values of CR, these suggest that there is no potential CR by intake of $\mathrm{Pb}$ and $\mathrm{Cd}$ for consumption of apples, but a slight concern for $\mathrm{CR}$ induced by $\mathrm{Ni}$ through the consumption of apples, since the levels of $\mathrm{CR}$ of $\mathrm{Ni}$ are in the lower limit established by USEPA [45].

The health risk assessments based on the results obtained from the Golden Delicious apple samples reveal that there are no significant potential health risks for the residents of this locality due to consumption of apples from the investigated establishments.

Natural and anthropogenic sources are increasing the levels of human exposure to heavy metals through the consumption of food contaminated with these metals, putting the health of the population at risk, for which reason constant monitoring measures for these contaminants should be established to prevent the possible risks associated with health derived from exposure to foods contaminated with heavy metals.

\section{Acknowledgements}

This work was financially supported by PRODEP (UNACAR-EXB-108).

\section{Conflicts of Interest}

The authors declare no conflicts of interest regarding the publication of this paper.

\section{References}

[1] Loutfy, N., Fuerhacker, M., Tundo, P., Raccanelli, S., El Dien, A.G. and Ahmed, 
M.T. (2006) Dietary Intake of Dioxins and Dioxin-Like PCBs, Due to the Consumption of Dairy Products, Fish/Seafood and Meat from Ismailia City, Egypt. Science of the Total Environment, 370, 1-8.

https://doi.org/10.1016/j.scitotenv.2006.05.012

[2] Wang, Q., Liu, J. and Cheng, S. (2015) Heavy Metals in Apple Orchard Soils and Fruits and Their Health Risk in Liaodong Peninsula, Northeast China. Environmental Monitoring and Assessment, 187, 4178.

https://doi.org/10.1007/s10661-014-4178-7

[3] Bini, C., Wahsha, M., Fontana, S. and Maleci, L. (2012) Effects of Heavy Metals on Morphological Characteristics of Taraxacum officinale Web Growing on Mine Soils in NE Italy. Journal of Geochemical Exploration, 123, 101-108.

https://doi.org/10.1016/j.gexplo.2012.07.009

[4] Bermudez, G.M.A., Jasan, R., Plá, R. and Pignata, M.L. (2012) Heavy Metals and Trace Elements in Atmospheric Fall-Out: Their Relationship with Topsoil and Wheat Element Composition. Journal of Hazardous Materials, 213-214, 447-456. https://doi.org/10.1016/j.jhazmat.2012.02.023

[5] Di Salvatore, M., Carafa, A.M. and Carratù, G. (2008) Assessment of Heavy Metals Phytotoxicity Using Seed Germination and Root Elongation Tests: A Comparison of Two Growth Substrates. Chemosphere, 73, 1461-1464.

https://doi.org/10.1016/j.chemosphere.2008.07.061

[6] Khan, A., Khan, S., Khan, M.A., Qamar, Z. and Waqas, M. (2015) The Uptake and Bioaccumulation of Heavy Metals by Food Plants, Their Effects on Plants Nutrients, and Associated Health Risk: A Review. Environmental Science and Pollution Research, 22, 13772-13799. https://doi.org/10.1007/s11356-015-4881-0

[7] Dyer, C.A. (2007) Heavy Metals as Endocrine-Disrupting Chemicals. In: Gore, A.C., Ed., Endocrine-Disrupting Chemicals. From Basic Research to Clinical Practice, Humana Press, Totowa, NJ, 111-133. https://doi.org/10.1007/1-59745-107-X_5

[8] IARC-International Agency for Research on Cancer (1993) Cadmium and Cadmium Compounds. In: IARC, Ed., Beryllium, Cadmium, Mercury and Exposure in the Glass Manufacturing Industry, International Agency for Research on Cancer, Lyon, 119-237.

[9] Nawab, J., Farooqi, S., Xiaoping, W., Khan, S. and Khan, A. (2018) Levels, Dietary Intake, and Health Risk of Potentially Toxic Metals in Vegetables, Fruits, and Cereal Crops in Pakistan. Environmental Science and Pollution Research, 25, 5558-5571. https://doi.org/10.1007/s11356-017-0764-x

[10] Hamurcu, M., Özcan, M.M., Dursun, N. and Gezgin, S. (2010) Mineral and Heavy Metal Levels of Some Fruits Grown at the Roadsides. Food and Chemical Toxicolo$g y$, 48, 1767-1770. https://doi.org/10.1016/j.fct.2010.03.031

[11] Nie, J.Y., Kuang, L.X., Li, Z.X., Xu, W.H., Wang, C., Chen, Q.S., Li, A., Zhao, X.B., Xie, H.Z., Zhao, D.Y., Wu, Y.L. and Cheng, Y. (2016) Assessing the Concentration and Potential Health Risk of Heavy Metals in China's Main Deciduous Fruits. Journal of Integrative Agriculture, 15, 1645-1655.

https://doi.org/10.1016/S2095-3119(16)61342-4

[12] Khan, K., Lu, Y., Khan, H., Ishtiaq, M., Khan, S., Waqas, M., Wei, L. and Wang, T. (2013) Heavy Metals in Agricultural Soils and Crops and Their Health Risks in Swat District, Northern Pakistan. Food and Chemical Toxicology, 58, 449-458. https://doi.org/10.1016/j.fct.2013.05.014

[13] Škrbić, B., Živančev, J. and Mrmoš, N. (2013) Concentrations of Arsenic, Cadmium and Lead in Selected Foodstuffs from Serbian Market Basket: Estimated Intake by 
the Population from the Serbia. Food and Chemical Toxicology, 58, 440-448. https://doi.org/10.1016/j.fct.2013.05.026

[14] Elbagermi, M.A., Edwards, H.G.M. and Alajtal, A.I. (2012) Monitoring of Heavy Metal Content in Fruits and Vegetables Collected from Production and Market Sites in the Misurata Area of Libya. International Scholarly Research Network Analytical Chemistry, 2012, Article ID: 827645. https://doi.org/10.5402/2012/827645

[15] Sobukola, O.P., Adeniran, O.M., Odedairo, A.A. and Kajihausa, O.E. (2010) Heavy Metal Levels of Some Fruits and Leafy Vegetables from Selected Markets in Lagos, Nigeria. African Journal of Food Science, 4, 389-393.

[16] Radwan, M.A. and Salama, A.K. (2006) Market Basket Survey for Some Heavy Metals in Egyptian Fruits and Vegetables. Food and Chemical Toxicology, 44, 1273-1278. https://doi.org/10.1016/j.fct.2006.02.004

[17] Llobet, J.M., Falcó, G., Casas, C., Teixidó, A. and Domingo, J.L. (2003) Concentrations of Arsenic, Cadmium, Mercury, and Lead in Common Foods and Estimated Daily Intake by Children, Adolescents, Adults, and Seniors of Catalonia, Spain. Journal of Agricultural and Food Chemistry, 51, 838-842. https://doi.org/10.1021/jf020734q

[18] Khan, S., Rehman, S., Khan, A.Z., Khan, M.A. and Shah, M.T. (2010) Soil and Vegetables Enrichment with Heavy Metals from Geological Sources in Gilgit, Northern Pakistan. Ecotoxicology and Environmental Safety, 73, 1820-1827. https://doi.org/10.1016/j.ecoenv.2010.08.016

[19] Arora, M., Kiran, B., Rani, S., Rani, A., Kaur, B. and Mittal, N. (2008) Heavy Metal Accumulation in Vegetables Irrigated with Water from Different Sources. Food Chemistry, 111, 811-815. https://doi.org/10.1016/j.foodchem.2008.04.049

[20] USDA (United States Department of Agriculture) (2018) Fresh Deciduous Fruit: World Markets and Trade (Apples, Grapes and Pears). Foreign Agricultural Services.

[21] Atlas Agroalimentario (2017) Consultado el 10 de Enero de 2019. http://nube.siap.gob.mx/gobmx_publicaciones_siap/pag/2017/Atlas-Agroalimentari o-2017

[22] Seipel, M., Pirovani, M.E., Güemes, D.R., Gariglio, N.F. and Piagentini, A.M. (2009) Características Fisicoquímicas de los Frutos de Tres Variedades de Manzanas Cultivadas en la Región Centro-Este de la Provincia de Santa Fe. FAVE Sección Ciencias Agrarias, 8, 27-36. https://doi.org/10.14409/fa.v8i1.1340

[23] Quideau, S., Deffieux, D., Douat-Casassus, C. and Pouységu, L. (2011) Plant Polyphenols: Chemical Properties, Biological Activities, and Synthesis. Angewandte Chemie International Edition, 50, 586-621. https://doi.org/10.1002/anie.201000044

[24] USEPA (United States Environmental Protection Agency) (1983) Methods for Chemical Analysis of Water and Wastes. National Technical Information Service, US Department of Commerce, Springfield, VA.

[25] Association of Official Agricultural Chemists (1999) International Accreditation Criteria for Laboratories Performing Food Chemistry Testing. Association of Official Agricultural Chemists, Gaithersburg, MD, 1-33.

[26] Jan, F.A., Ishaq, M., Khan, S., Ihsanullah, I., Ahmad, I. and Shakirullah, M. (2010) A Comparative Study of Human Health Risks via Consumption of Food Crops Grown on Wastewater Irrigated Soil (Peshawar) and Relatively Clean Water Irrigated Soil (Lower Dir). Journal of Hazardous Materials, 179, 612-621. https://doi.org/10.1016/j.jhazmat.2010.03.047

[27] Khan, S., Cao, Q., Zheng, Y.M., Huang, Y.Z. and Zhu, Y.G. (2008) Health Risks of 
Heavy Metals in Contaminated Soils and Food Crops Irrigated with Wastewater in Beijing, China. Environmental Pollution, 152, 686-692. https://doi.org/10.1016/j.envpol.2007.06.056

[28] Roba, C., Roşu, C., Piştea, I., Ozunu, A. and Baciu, C. (2016) Heavy Metal Content in Vegetables and Fruits Cultivated in Baia Mare Mining Area (Romania) and Health Risk Assessment. Environmental Science and Pollution Research, 23, 6062-6073. https://doi.org/10.1007/s11356-015-4799-6

[29] Cherfi, A., Abdoun, S. and Gaci, O. (2014) Food Survey: Levels and Potential Health Risks of Chromium, Lead, Zinc and Copper Content in Fruits and Vegetables Consumed in Algeria. Food and Chemical Toxicology, 70, 48-53. https://doi.org/10.1016/j.fct.2014.04.044

[30] Wang, X., Sato, T., Xing, B. and Tao, S. (2005) Health Risks of Heavy Metals to the General Public in Tianjin, China via Consumption of Vegetables and Fish. Science of the Total Environment, 350, 28-37.

https://doi.org/10.1016/j.scitotenv.2004.09.044

[31] Onuoha, S.C., Anelo, P.C. and Nkpaa, K.W. (2015) Human Health Risk Assessment of Heavy Metals in Snail (Archachatina marginata) from Four Contaminated Regions in Rivers State, Nigeria. American Chemical Science Journal, 11, 1-8. https://doi.org/10.9734/ACSJ/2016/22163

[32] Nasreddine, L., Nashalian, O., Naja, F., Itani, L., Parent-Massin, D., Nabhani-Zeidan, M. and Hwalla, N. (2010) Dietary Exposure to Essential and Toxic Trace Elements from a Total Diet Study in an Adult Lebanese Urban Population. Food and Chemical Toxicology, 48, 1262-1269. https://doi.org/10.1016/j.fct.2010.02.020

[33] Muñoz, O., Bastias, J.M., Araya, M., Morales, A., Orellana, C., Rebolledo, R. and Velez, D. (2005) Estimation of the Dietary Intake of Cadmium, Lead, Mercury, and Arsenic by the Population of Santiago (Chile) Using a Total Diet Study. Food and Chemical Toxicology, 43, 1647-1655. https://doi.org/10.1016/j.fct.2005.05.006

[34] Okorie, E. and Ochinimhe, J. (2014) Assessment of Some Imported Apple Fruits (Malus domestica) Commonly Sold in Nigeria for Alkaline and Trace Metal Contents. International Journal of Biological and Chemical Sciences, 8, 1239-1242. https://doi.org/10.4314/ijbcs.v8i3.35

[35] Altundag, H. and Tuzen, M. (2011) Comparison of Dry, Wet and Microwave Digestion Methods for the Multi Element Determination in Some Dried Fruit Samples by ICP-OES. Food and Chemical Toxicology, 49, 2800-2807. https://doi.org/10.1016/j.fct.2011.07.064

[36] Onianwa, P.C., Adeyemo, A.O., Idowu, O.E. and Ogabiela, E.E. (2001) Copper and Zinc Contents of Nigerian Foods and Estimates of the Adult Dietary Intakes. Food Chemistry, 72, 89-95. https://doi.org/10.1016/S0308-8146(00)00214-4

[37] Parveen, Z., Khuhro, M.I. and Rafiq, N. (2003) Market Basket Survey for Lead, Cadmium, Copper, Chromium, Nickel, and Zinc in Fruits and Vegetables. Bulletin of Environmental Contamination and Toxicology, 71, 1260-1264. https://doi.org/10.1007/s00128-003-8640-4

[38] FAO/WHO (2001) Codex Alimentarius Commission. In: FAO/WHO, Ed., Joint FAO/ WHO Food Standards Program, ALI-NORM 01/12A, Codex Alimentarius Commission, Geneva, Switzerland, 1-289.

[39] Nordberg, G.F., Bernard, A., Diamond, G.L., Duffus, J.H., Illing, P., Nordberg, M., Bergdahl, I.A., Jin, T. and Skerfving, S. (2018) Risk Assessment of Effects of Cadmium on Human Health (IUPAC Technical Report). Pure and Applied Chemistry, 90, 755-808. https://doi.org/10.1515/pac-2016-0910 
[40] Mezynska, M. and Brzóska, M.M. (2018) Environmental Exposure to Cadmium-A risk for Health of the General Population in Industrialized Countries and Preventive Strategies. Environmental Science and Pollution Research, 25, 3211. https://doi.org/10.1007/s11356-017-0827-Z

[41] Srivastava, A., Siddiqui, N.A., Koshe, R.K. and Singh, V.K. (2018) Human Health Effects Emanating from Airborne Heavy Metals Due to Natural and Anthropogenic Activities: A Review. In: Siddiqui, N., Tauseef, S. and Bansal, K., Eds., Advances in Health and Environment Safety, Springer Transactions in Civil and Environmental Engineering, Springer, Singapore. https://doi.org/10.1007/978-981-10-7122-5_29

[42] Mapanda, F., Mangwayana, E.N., Nyamangara, J. and Giller, K.E. (2007) Uptake of Heavy Metals by Vegetables Irrigated Using Wastewater and the Subsequent Risks in Harare, Zimbabwe. Physics and Chemistry of the Earth, Parts $A / B / C, 32$, 1399-1405. https://doi.org/10.1016/j.pce.2007.07.046

[43] Balkhair, K.S. and Ashraf, M.A. (2016) Field Accumulation Risks of Heavy Metals in Soil and Vegetable Crop Irrigated with Sewage Water in Western Region of Saudi Arabia. Saudi Journal of Biological Sciences, 23, S32-S44. https://doi.org/10.1016/j.sjbs.2015.09.023

[44] Qureshi, A.S., Hussain, M.I., Ismail, S. and Khan, Q.M. (2016) Evaluating Heavy Metal Accumulation and Potential Health Risks in Vegetables Irrigated with Treated Wastewater. Chemosphere, 163, 54-61. https://doi.org/10.1016/j.chemosphere.2016.07.073

[45] USEPA (United States Environmental Protection Agency) (2011) Screening Level (RSL) for Chemical Contaminant at Superfound Sites. 